\title{
Morfologia dos estágios imaturos de Eupalea reinhardti Crotch (Coleoptera, Coccinellidae) e alguns dados biológicos ${ }^{1}$
}

\author{
Flávia de Albuquerque Seródio Ferreira ${ }^{2}$ \\ Lúcia Massutti de Almeida ${ }^{2}$
}

\begin{abstract}
Morphology of immature stages of Eupalea reinhardti Crotch (Coleoptera, Coccinellidae) and some biological data. A morphological study of the immature stages of Eupalea reinhardti Crotch, 1874 is presented. Morphological information is discussed and biological data are included. The immature stages are compared with those of other genera of Coccinellidae.

KEY WORDS. Eupalea reinhardti, morphology, immature stages, biological data
\end{abstract}

O gênero Eupalea Mulsant, 1850 é formado por 15 espécies, seis delas ocorrendo no Brasil. ALMEIDA \& GORDON (1990) revisaram o gênero onde descreveram quatro espécies novas e redescreveram as demais. As informações sobre a biologia das espécies do gênero são muito escassas.

Adultos de Eupalea reinhardti Crotch, 1874 foram coletados em Maringá, Paraná, predando Psylla sp. (Homoptera, Psyllidae) em sibipiruna, Caesalpinia peltophoroides Benth (Caesalpiniaceae). Estes mesmos psilídeos são encontrados sugando a seiva de Tipuana tipu (Benth) Kuntze (Fabaceae), espécie também utilizada na arborização das áreas urbanas das cidades do Paraná.

As formas imaturas foram obtidas em criação em câmaras climatizadas e alguns aspectos biológicos foram observados. Os ovos, larvas e pupas foram fixados em Kahle-Dietrich. Para o estudo da morfologia os exemplares foram fervidos em hidróxido de potássio a $10 \%$ por alguns segundos, lavados em água destilada e em seguida dissecados com auxílio de pinças e estiletes. Os desenhos foram obtidos em câmara clara acoplada em microscópio estereoscópico Wild M5 e microscópio Wild M20. As fotografias foram obtidas com material vivo, em microscópio Olympus PM-20 e para isso, larvas, pupas e adultos foram imobilizados em freezer por 10 segundos. As fotos de varredura foram realizadas no Centro de Microscopia Eletrônica da Universidade Federal do Paraná. Com o auxílio de microscopia óptica e eletrônica de varredura foi possível, através de técnicas específicas de preparação, a visualização de estruturas importantes à sua caracterização.

Os principais caracteres utilizados foram as placas tergais do tórax e abdome, mandíbula e armaduras larvais, estruturas ainda não descritas para esta espécie. Os principais caracteres são discutidos e comparados com os utilizados para outras

1) Contribuição número 1106 do Departamento de Zoologia, Universidade Federal do Paraná.

2) Departamento de Zoologia, Universidade Federal do Paraná. Caixa Postal 19020, 81531-990 Curitiba, Paraná, Brasil. Bolsistas da CAPES e CNPq, respectivamente. 
espécies de coccinelídeos predadores, potencialmente importantes no controle biológico, descritos em REES et al. (1994). O estudo de formas imaturas, com análise de caracteres são muito pouco representativos em Coccinellidae. Os trabalhos mais importantes para o conhecimento de formas imaturas são os de GAGE (1920), ALMEIDA \& RibEiro (1986), RibEIRo \& AlmeidA (1989) e ReEs et al. (1994).

\section{Morfologia}

Ovo. Cório com superfície reticulada, esbranquiçada (Fig. 10); comprimento $1,04 \mathrm{~mm}$; maior largura $0,46 \mathrm{~mm}$.

Larva de quarto ínstar. Corpo alongado, achatado dorso-ventralmente, de coloração amarelada e com placas tergais castanhas escuras, quase negras, de tamanhos variados, com paraescolos e estrumas (Fig. 1). Ventralmente sem placas ou máculas e com região gular bem distinta (Fig. 5). Cabeça quadrangular com bordos arredondados, de coloração basal castanho escura e finas cerdas claras (Fig. 3). Três ocelos de cada lado da cabeça, subcônicos, dispostos em fileira logo atrás da antena. Antena com três artículos distintos (Fig. 7), o primeiro mais largo, de comprimento aproximadamente igual à metade do segundo, este com três cerdas apicais, artículo apical em forma de espinho largo e de ápice arredondado. Mandíbula muito esclerotinizada, com base larga e ápice afilado (Fig. 4); área central da prosteca com dentículos; mola em forma de dente acuminado e com inúmeras microcerdas dispostas em fileira; côndilo com uma cerda longa na base e outra disposta pouco acima, com um quarto do tamanho da primeira.

Pronoto com duas placas laterais escuras, com um paraescolo de cada lado e inúmeras calazes escuras. Meso e metanoto, cada um com duas placas laterais escuras e sobre cada uma delas um paraescolo com muitas calazes. Região dorsal do pro, meso e metanoto com uma faixa longitudinal amarelada e sobre esta algumas calazes com cerdas escuras (Fig. 11). Pro, meso e metatórax amarelados com áreas escurecidas ao redor da base das coxas e cada um com verrucas escuras e cerdas claras. Meso e metapleuras com estrumas e poucas cerdas claras. Pernas negras com pilosidade esbranquiçada, coxas transversais, trocanter e fêmur pouco maiores que as tíbias. Garra com dente basal subquadrado e ápice em ponta afilada e recurvada em direção à base (Fig. 6).

Abdome. Quarto primeiros segmentos com quatro placas tergais escuras cada um (Fig. 11): as duas externas com paraescolos pouco menores que os do tórax e as duas internas com estrumas e três cerdas (Figs 1 e 9). Os quatro outros segmentos abdominais com quatro placas tergais cada um: as duas externas escuras com paraescolos de tamanho aproximadamente iguais aos dos segmentos anteriores e as duas internas de coloração branca amarelada com estrumas com três cerdas escuras de diferentes tamanhos, algumas representadas por pontos. Último segmento abdominal com duas placas tergais escuras, cada uma com um paraescolo e cerdas de tamanhos variados, escuras e claras. Cada externo abdominal com seis verrucas, as duas mais externas de coloração escura e maiores e as duas centrais menores e de mesma coloração do tegumento. Pleuras abdominais com paraescolos e cerdas branco amareladas. Espiráculos abdominais anulares com cerdas finas e sem calazes (Fig. 8). 

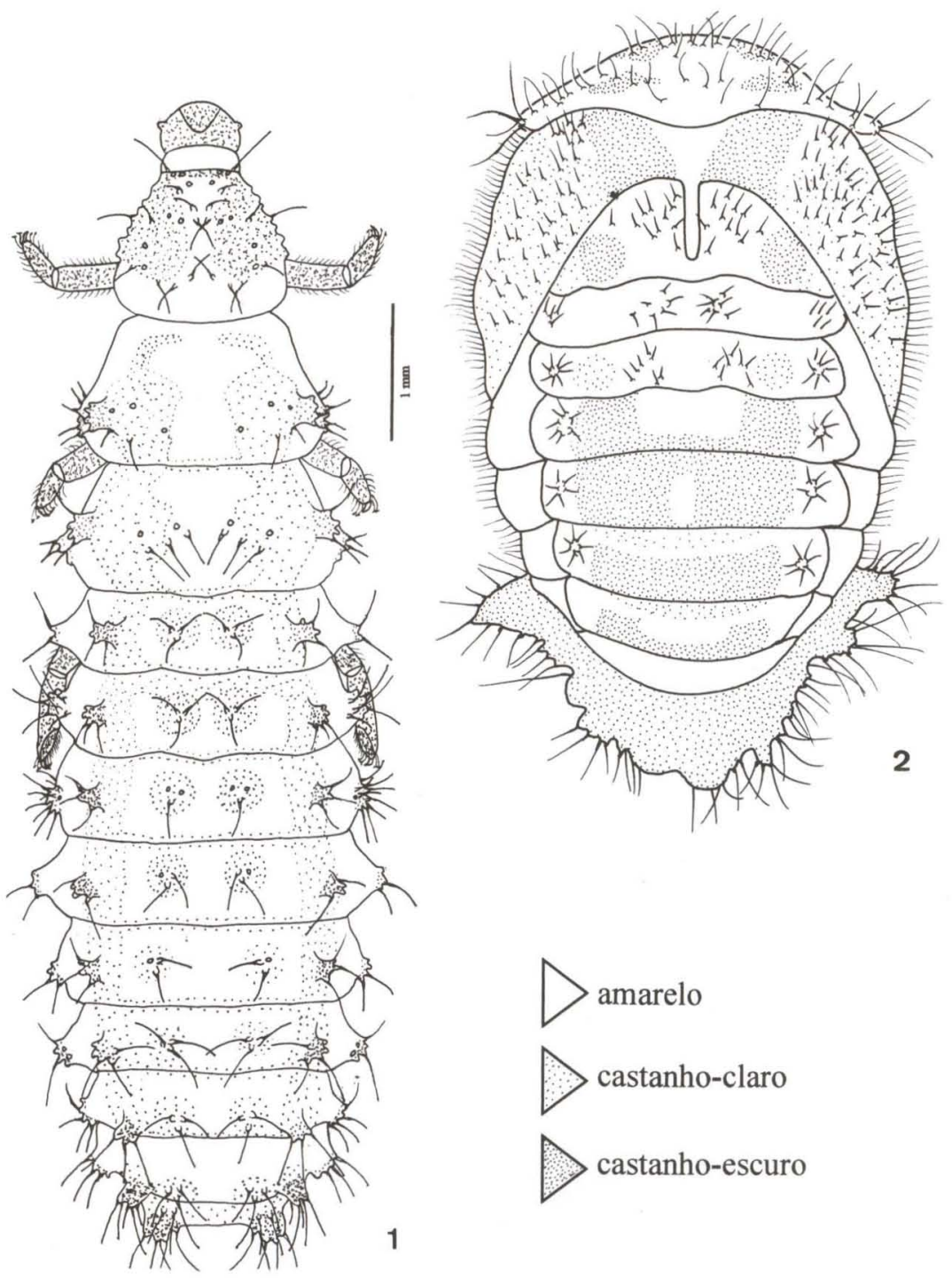

Figs 1-2. Eupalea reinhardti. (1) Larva, vista dorsal; (2) pupa, vista dorsal.

Pupa. Amarelo clara com áreas marrom acinzentadas escuras no tórax, pteroteca e partes do abdome, com muitas cerdas finas e esbranquiçadas (Figs $2 \mathrm{e}$ 12); comprimento $5,08 \mathrm{~mm}$ e maior largura $3,25 \mathrm{~mm}$. Contorno ovalado, convexa e região anterior truncada. Cabeça projetada para baixo, castanha escura, com longas cerdas esbranquiçadas. Pronoto amarelado com inúmeras cerdas e quatro máculas negras arredondadas: duas pequenas apicais e duas maiores basais. Meso e metanoto amarelados, o mesonoto com duas máculas arredondadas castanhas escuras. Pteroteca pardas com duas faixas basais marrom acinzentadas. Pernas de mesma colora- 

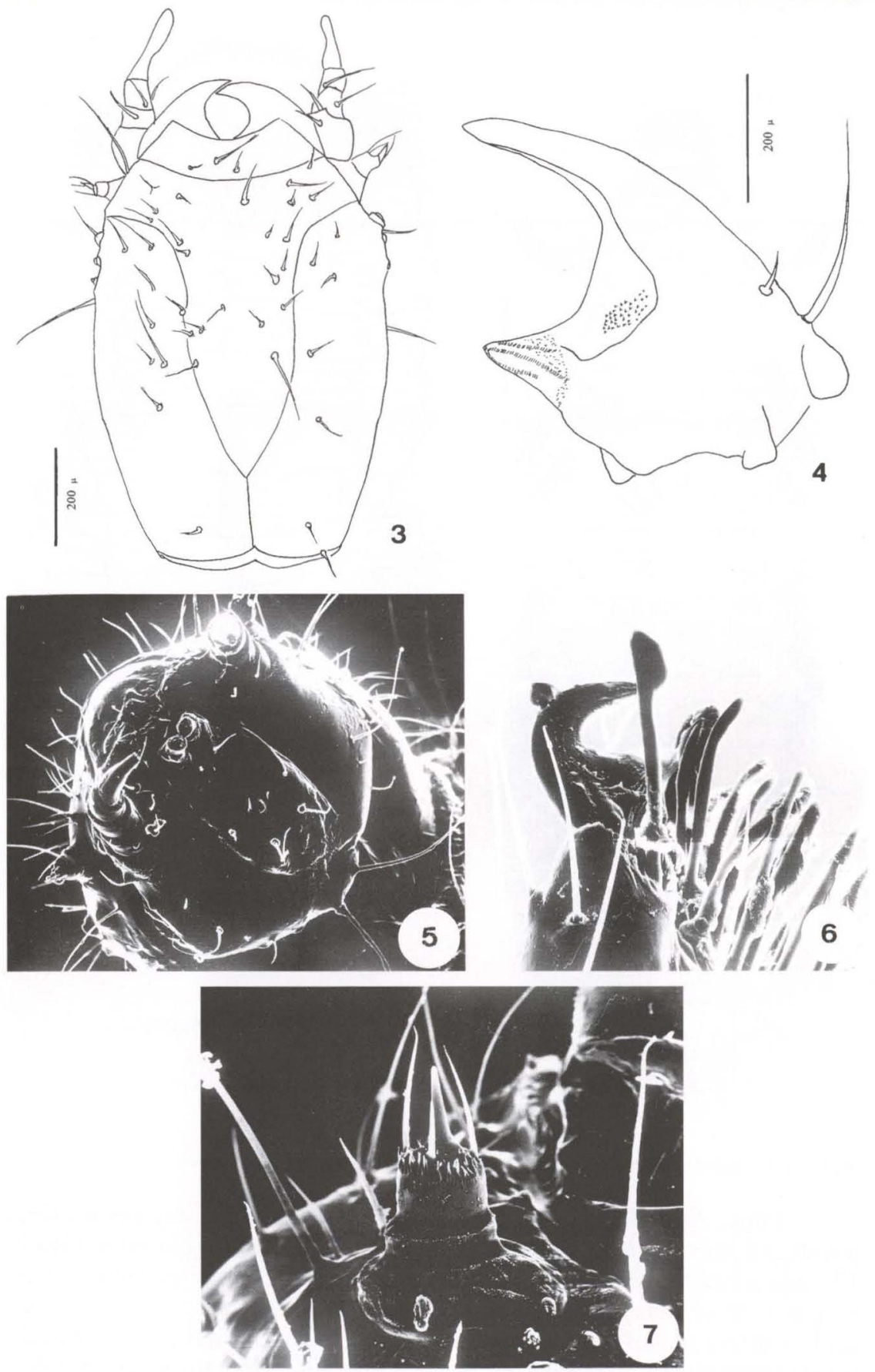

Figs 3-7. Eupalea reinhardti, larva. (3) Cabeça, vista dorsal; (4) mandibula; (5) cabeça, vista ventral; (6) garra tarsal; (7) antena. 
ção dos élitros com ápice do fêmur e base da tíbia escuras. Abdome amarelado, primeiro tergo com duas máculas arredondadas castanhas, segundo a quinto tergos com faixas transversais castanhas; esternos abdominais amarelados.
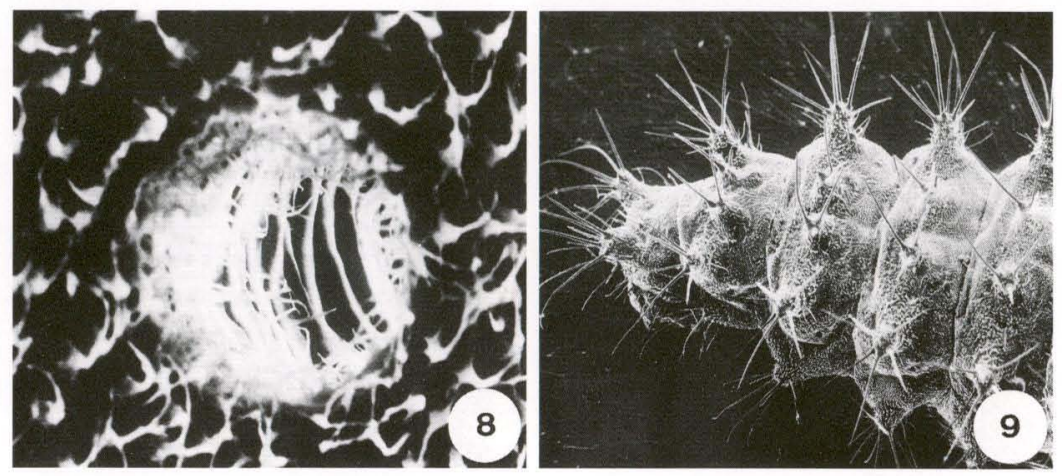

Figs 8-9. Eupalea reinhardti. (8) Espiráculo abdominal; (9) abdome, vista dorsal.

\section{Dados biológicos}

Os ovos, larvas e adultos de Eupalea reinhardti foram coletadas em folhas de Caesalpinia peltophoroides e Tipuana tipu, alimentando-se vorazmente de Psylla sp. (Homoptera, Psyllidae) (Fig. 13), em abril e maio de 1997, em Maringá, Paraná. Em laboratório as fềmeas fizeram as posturas nas folhas de Caesalpinia peltophoroides (Fig. 10) ou no substrato que forrava o recipiente, isolados ou em pequenos grupos de no máximo 23 ovos. As folhas foram coletadas em Curitiba, no campus da Universidade Federal do Paraná e substituídas a cada dois dias. As larvas (Fig. 11) desenvolvem-se em cerca de 28 dias e sofrem três mudas. No quarto ínstar a larva prende-se ao substrato, torna-se imóvel, transforma-se em pupa (Fig. 12) e permanece ligada à exúvia do quarto ínstar larval (Fig. 2). As pupas apresentam um desenvolvimento de cerca de cinco dias, quando emerge o adulto (Fig. 13) que imediatamente sai à procura dos psilídeos para se alimentar. Larvas e pupas apresentam coloração parda no início do seu desenvolvimento e depois de algumas horas adquirem sua cor definitiva.

\section{DISCUSSÃO E CONCLUSÕES}

Os únicos trabalhos que tratam da análise de estruturas larvais com auxílio de microscopia eletrônica são os de ALMEIDA \& RiBEIRo (1986) e RIBEIRO \& ALMEIDA (1989) que estudaram Epilachna cacica Guérin, 1844 e Epilachna spreta (Mulsant, 1850). Com base nestes trabalhos pode-se comparar o espiráculo abdominal que se apresenta muito semelhante àquelas espécies, do tipo anular, porém em E. reinhardti não ocorrem calazes ligadas ao espiráculo. As antenas dessas duas espécies também apresentam três artículos, porém muito mais longos e afilados. As mandíbulas diferem significativamente nas duas anteriores, com cinco dentes apicais, características de espécies fitófagas, ao contrário de E. reinhardti que 

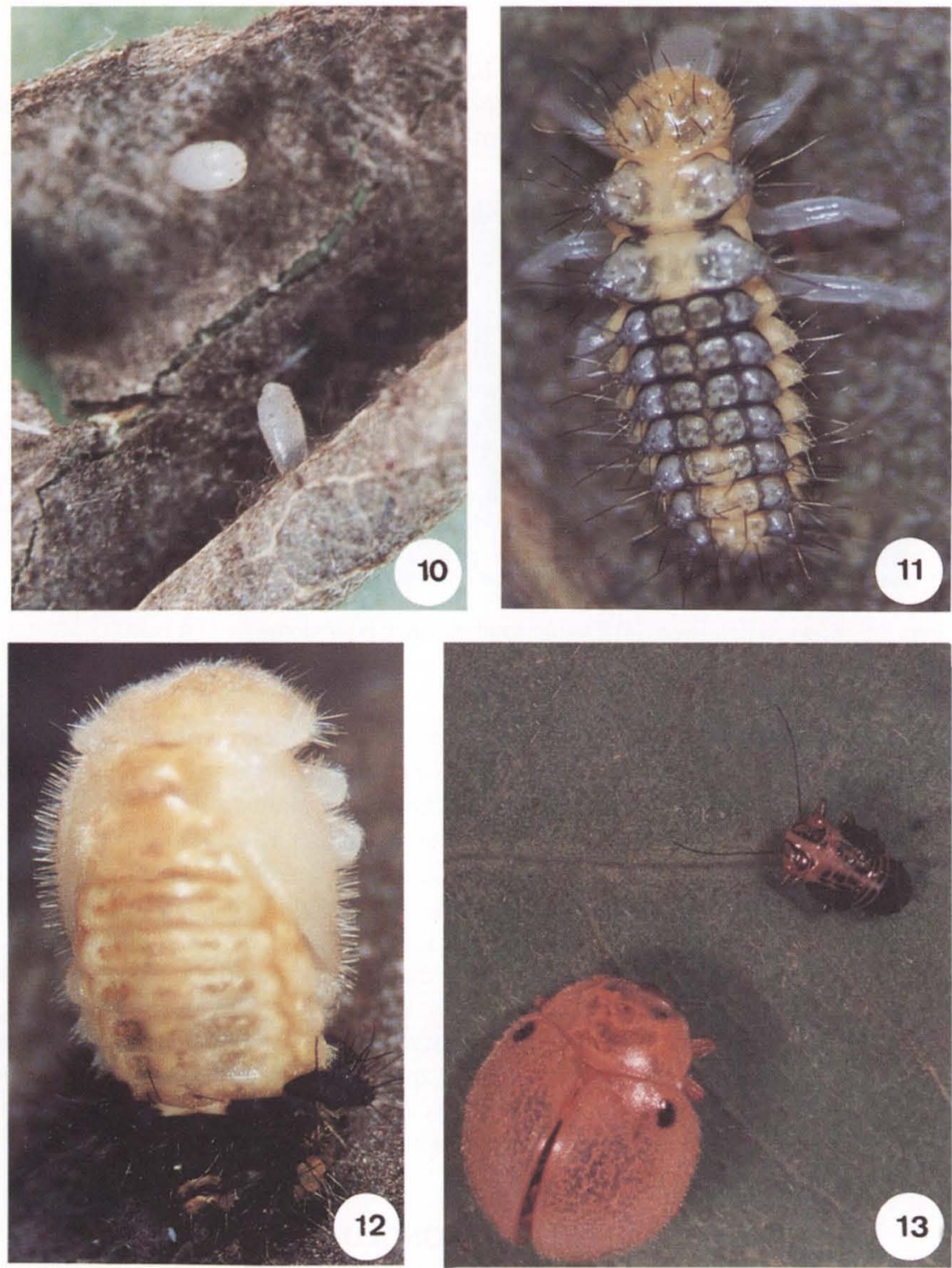

Figs 10-13. Eupalea reinhardti em folha de Tipuana tipu. (10) Ovos; (11) larva de quarto instar; (12) pupa; (13) adulto e Psylla sp. (Homoptera, Psyllidae).

apresenta mandíbula típica de predador. A mandíbula de E. reinhardti apresenta prosteca com dentículos e mola em forma de dente acuminado com microcerdas, diferindo da mandíbula das espécies de Epilachna.

REES et al. (1994), embasados na terminologia de GAGE (1920), ilustraram e apresentaram chave de identificação para 46 gêneros de Coccinellidae norte-americanos, onde utilizaram importantes caracteres como as placas dorsais da parede 
do corpo e suas diferentes projeções e cerdas. Com base nesses trabalhos foi possível a comparação de E. reinhardti com as de outros gêneros de predadores. Eupalea reinhardti apresenta caracteres comparáveis aos das espécies de Hippodamia Mulsant, 1846 e de Harmonia Mulsant, 1850, predadores de afídeos e coccídeos. Eupalea reinhardti assemelha-se a Hippodamia pelo tipo de paraescolos do tergo abdominal que são pequenos e robustos e também à Harmonia pelo tipo de conformação e distribuição das placas tergais. A mandíbula de E. reinhardti é do tipo da de Rhyzobius Stephens, 1831 e Chilocorus Leach, 1815 que se alimentam de coccídeos, mas difere de ambos por apresentar apenas um dente apical muito afilado e a região da prosteca com dentículos.

ALMEIDA \& GORDON (1990) afirmaram que não há dados sobre hospedeiros das espécies de Eupalea. A única referência existente, de FrAGA et al. (1986) indica E. reinhardti alimentando-se de Psylla sp., constrastando com os de outras espécies de coccinelídeos predadores, os quais, mais comumente, alimentam-se de afídeos ou de coccídeos.

O período médio de desenvolvimento larval foi de sete dias e o pupal de cinco dias. O comportamento das fêmeas bem como o desenvolvimento de Eupalea reinhardti pode ser comparado à outras espécies predadoras. SANTOS \& PINTO (1981) e SiLva \& BARBOSA (1984) mostraram que o comportamento das fêmeas de Zagreus bimaculosus (Mulsant, 1850) e Cycloneda sanguinea (Linnaeus, 1763) foi semelhante às fêmeas de $E$. reinhardti com relação as posturas realizadas em laboratório. O período médio de desenvolvimento larval de Zagreus bimaculosus e Cycloneda sanguinea, foi respectivamente, 9,3 e 13,53 dias, sendo portanto maior. As pupas de $C$. sanguinea apresentaram um período de desenvolvimento menor $(3,4$ dias) comparado com as de E. reinhardti de cerca de cinco dias.

Eupalea reinhardti pode ser considerada potencialmente importante como espécie controladora de psilídeos, pois, tanto na fase jovem como na fase adulta, é um predador voraz. Porém, seu potencial predatório e a capacidade de busca pela presa, sob condições naturais ainda necessitam ser pesquisados minuciosamente para se conhecer a sua capacidade de atuação no controle biológico. Uma das características importantes observadas é a especificidade do alimento (HODEK \& HONEK 1996), pois $E$. reinhardti não se alimentou quando foram oferecidos afideos ou coccídeos ao invés de psilídeos.

\section{REFERÊNCIAS BIBLIOGRÁFICAS}

Almeida, L.M. \& C.S. Ribeiro. 1986. Morfologia dos estágios imaturos de Epilachna cacica Guérin, 1844 (Coleoptera, Cociinellidae). Revta bras. Ent. 30 (1): 43-49.

Almeida, L.M.\& R.D. Gordon. 1990. The Coccinellidae (Coleoptera) of South America. Part II. A Revision of the Genus Eupalea Mulsant, 1850 (Coleoptera, Coccinellidae). Revta bras. Ent. 34 (2): 313-330.

Fraga, A.I.A.; E. BerTI FILHO \& A.I. Ciociola. 1986. Nota sobre a ocorrência de Eupalea reinhardti Crotch (Coleoptera, Coccinellidae) atacando Psylla sp. (Homoptera, Psyllidae) em sibipiruna (Caesalpinia peltophoroides Benth). Revta Agricultura, Piracicaba, 61: 1-92.

Gage, J.H. 1920. The larvae of the Coccinellidae. Univ. Illinois Biol. Monographs 6: 232-294.

HodEk, I. \& A Honek.1996. Ecology of Coccinellidae. Dordrecht, Kluwer Academic Publishers, 464p. REES, B.E.; D.M. ANDERson; D. Bouk \& R.D. Gordon. 1994. Larval key to genera and selected of 
North American Coccinellidae (Coleoptera). Proc. Entomol. Soc. Wash. 96 (3): 387-412.

RIBEIRO, C.S. \& L.M. AlmeIDA. 1989. Descrição dos estágios imaturos de Epilachna spreta (Mulsant,

1850) (Coleoptera, Coccinellidae), com redescrição, comentários e chave para três outras espécies.

Revta bras. Zool. 6 (1): 99-110.

SANTOS, G.P. \& A.C.Q. PINTO. 1981. Biologia de Cycloneda sanguinea e sua associação com pulgão em mudas de mangueira. Pesq. Agropec. Bras., Brasília, 16 (4): 473-476.

Silva, C.C.A. DA \& S.M. BARBoSA DE L. 1984. Ciclo biológico de Zagreus bimaculosus (Muls.) (Coleoptera, Coccinellidae), um predador da cochonilha da palma forrageira Diaspis echinocacti (Bouché 1833). Bol. Pesquisa 2: 1-15.

Recebido em 08.VII.1999; aceito em 20.III.2000. 